\title{
Development of Interprofessional Graduate Health Professions Education Programs: Findings From a Needs Assessment
}

\author{
Emmanuelle Careau ${ }^{1,2,3}$, Isabelle Savard ${ }^{1}$ \& Holly O. Witteman ${ }^{1,4}$ \\ ${ }^{1}$ Faculty of Medicine, Université Laval, Québec City, Canada \\ ${ }^{2}$ Centre for Interdisciplinary Research in Rehabilitation and Social Integration (CIRRIS), Québec \\ City, Canada \\ ${ }^{3}$ Réseau de Collaboration sur les Pratiques Interprofessionnelles en Santé et Services Sociaux \\ (RCPI), Québec City, Canada \\ ${ }^{4}$ Research Centre of the CHU de Québec, Québec City, Canada
}

\begin{abstract}
It is increasingly necessary to equip healthcare professionals to engage in collaboration via interprofessional education (IPE). This paper describes the findings of a mixed-methods pedagogical needs assessment in health professions education, in which IPE emerged as a key theme. Two new graduate programs aim to meet these needs.
\end{abstract}

In 2010, the Lancet Commission proposed a number of health reforms in order to better face the challenges of 21st century healthcare. ${ }^{1}$ Proposed reforms included the adoption of competencydriven approaches and transformative learning, the promotion of interprofessional education, the use of information technology for learning, development of academic leadership and development of a new set of competencies around social accountability and system transformation. A key challenge of such reforms is how to best equip health professions educators to enact new pedagogical challenges. ${ }^{2-7}$

To respond to the challenges facing educators in academic and clinical settings, Laval University (Quebec City, Canada) has developed graduate programs in health professions education: a short program (12 credits) as well as a master's degree program. The programs are open to educators from all clinical disciplines. In this article, we describe a mixed-methods needs assessment conducted to identify pedagogical needs for these programs. We specifically highlight and discuss findings relevant

Corresponding author: Emmanuelle Careau, OT, $\mathrm{PhD}$, Centre for interdisciplinary research in rehabilitation and social integration (CIRRIS) 525 boul. Wilfrid-Hamel, Québec, Canada, G1M2S8.

Tel: +1-418-529-9141; Fax: +1-418-529-3548; Email:

Emmanuelle.Careau@rea.ulaval.ca to interprofessional education (IPE), which emerged as a key theme.

The needs assessment began with semi-structured focus groups, conducted within a sample of potential or actual health professions educators. Focus groups allow for the collection of rich data and their use is recommended when evaluating needs of potential learners. ${ }^{8}$ Participants were recruited via general invitation emails sent to all educators involved in health training programs at the university.

Five focus groups were held, each lasting approximately 90 minutes and involving eight to 11 participants (total $\mathrm{N}=48$ ), between September 19th and October 13th, 2011. Following each focus group, participants completed questionnaires to quantitatively assess interest in topics identified. Table 1 presents key characteristics of the participants. The sample population approximately reflected the balance of roles within the faculty of health sciences, for example, status (professors, clinical instructors, etc.) and disciplines (medicine, nursing, rehabilitation sciences, etc.) 


\begin{tabular}{|c|c|c|}
\hline \multicolumn{2}{|c|}{ Participants characteristics } & n (\%) \\
\hline \multicolumn{3}{|c|}{ Gender } \\
\hline & Women & $37(77 \%)$ \\
\hline & Men & $11(23 \%)$ \\
\hline \multicolumn{3}{|l|}{ Age } \\
\hline & $25-34$ & $14(29 \%)$ \\
\hline & $35-44$ & $15(31 \%)$ \\
\hline & $45-54$ & $14(29 \%)$ \\
\hline & $55-64$ & $5(10 \%)$ \\
\hline & $65+$ & - \\
\hline \multicolumn{3}{|c|}{$\begin{array}{l}\text { Status (participants may have }>1 \\
\text { status) }\end{array}$} \\
\hline & Professor & $14(29 \%)$ \\
\hline & Clinical instructor & $13(27 \%)$ \\
\hline & Residency supervisor & $7(15 \%)$ \\
\hline & Head of practical training & $6(13 \%)$ \\
\hline & Lecturer & $4(8 \%)$ \\
\hline & Medical resident & $3(6 \%)$ \\
\hline & $\begin{array}{l}\text { Other (e.g., program } \\
\text { director, clinic monitor, } \\
\text { training coordinator, etc.) }\end{array}$ & $11(23 \%)$ \\
\hline \multicolumn{3}{|c|}{ Disciplines } \\
\hline & Medicine & $26(54 \%)$ \\
\hline & Nursing & $7(15 \%)$ \\
\hline & Occupational therapy & $7(15 \%)$ \\
\hline & Physiotherapy & $5(10 \%)$ \\
\hline \multicolumn{3}{|c|}{$\begin{array}{l}\text { Years of university teaching } \\
\text { experience }\end{array}$} \\
\hline & $O-4$ & $11(23 \%)$ \\
\hline & $5^{-14}$ & $19(40 \%)$ \\
\hline & $15^{+}$ & $18(38 \%)$ \\
\hline \multicolumn{3}{|c|}{ Involvement in teaching activities } \\
\hline & $\begin{array}{l}\text { Ongoing, at least several } \\
\text { hours per week }\end{array}$ & $28(58 \%)$ \\
\hline & $\begin{array}{l}\text { Periodic, intense burst of } \\
\text { teaching activity }\end{array}$ & $14(29 \%)$ \\
\hline & $\begin{array}{l}\text { Occasional (e.g. several } \\
\text { half-days per year) }\end{array}$ & $6(13 \%)$ \\
\hline Total & & 48 \\
\hline
\end{tabular}

Table 1. Study population

Discussions during the focus groups were structured around two topics: 1) perceived relevance and receptiveness toward a new graduate program on health professions education; 2) subjects of interest. Discussions were transcribed, compared with notes taken during the focus groups and validated by the group facilitator and co-facilitator. Data from questionnaires and focus groups were triangulated to draw conclusions.
Several themes emerged that support the overall importance of graduate programs in health professions education. It was noted that there is a growing need for experts in pedagogy in clinical settings. Study participants suggested that this kind of program would help to train the next generation of health educators in order that they might demonstrate a wide range of competencies and participate in diverse and innovative pedagogical strategies. Several participants also mentioned that a master's degree in pedagogy could serve as a springboard for those interested in pursuing a research career in this field. Participants indicated that it is essential to have a diversity of well-trained and well-equipped health educators in order to improve the current pedagogical practices in health sciences and foster clinical innovations in complex contexts.

Participants showed greater interest toward a short program than toward a master's degree. Examining responses across disciplines, we observed that $100 \%$ of participants in nursing, $80 \%$ of those in rehabilitation and $71 \%$ of those in medicine were interested in participating in a short program (see Table 2). Differences in proportions were not statistically significant (Fisher's exact test: $p=.55$ ), suggesting that an interprofessional program in health professions education may be attractive across clinical disciplines. Indeed, the interprofessional nature of this kind of program was specifically noted as appealing to participants. Focus group participants explained that they saw such programs as opportunities for sharing experiences and tools, breaking down disciplinary silos, and truly promoting collaborative practices. As noted in Table 2, 71\% of respondents indicated, in the subsequent questionnaire, that they were interested in learning more about IPE and collaborative practices.

The overall positive views toward IPE and collaborative practices are encouraging, given that many benefits have been noted when students in the health professions learn with, from and about each other. In a recent Cochrane systematic literature review on the effectiveness of IPE, positive outcomes emerged in a range of contexts such as diabetes care; emergency department culture and patient satisfaction; collaborative team behavior and reduction of clinical error rates for emergency department teams; collaborative team behavior in operating rooms; management of care delivered in cases of domestic violence; and mental health practitioner competencies related to the delivery of patient care.9,10 Furthermore, participation in IPE activities provides valuable practical experience 
while also engendering a more positive attitude toward IPE and suggesting greater intent to pursue further engagement in IPE. ${ }^{11}$ Accordingly, many health professions education programs are implementing IPE activities within their curricula and accreditation standards have been established to guide such programs. ${ }^{12}$

\begin{tabular}{|c|c|c|c|c|c|}
\hline Interest of respondents & $\begin{array}{c}\text { Not } \\
\text { interested } \\
\text { at all }\end{array}$ & $\begin{array}{l}\text { Not very } \\
\text { interested }\end{array}$ & $\begin{array}{l}\text { Somewhat } \\
\text { interested }\end{array}$ & $\begin{array}{c}\text { Very } \\
\text { interested }\end{array}$ & $\begin{array}{c}\text { I } \\
\text { don't } \\
\text { know }\end{array}$ \\
\hline \multicolumn{6}{|l|}{$\begin{array}{l}\text { Toward an interprofessional short } \\
\text { program }\end{array}$} \\
\hline Medicine & $1(5 \%)$ & $4(19 \%)$ & $7(33 \%)$ & $8(38 \%)$ & $1(5 \%)$ \\
\hline Nursing & - & - & $2(33 \%)$ & $4(67 \%)$ & - \\
\hline Rehabilitation & - & $2(13 \%)$ & $6(40 \%)$ & $6(40 \%)$ & $1(7 \%)$ \\
\hline Total & $1(5 \%)$ & $6(14 \%)$ & $15(36 \%)$ & $18(43 \%)$ & $2(5 \%)$ \\
\hline \multicolumn{6}{|l|}{$\begin{array}{l}\text { Toward an interprofessional } \\
\text { master's degree }\end{array}$} \\
\hline Medicine & $2(8 \%)$ & $11(46 \%)$ & $2(8 \%)$ & $7(29 \%)$ & $2(8 \%)$ \\
\hline Nursing & $1(17 \%)$ & - & $3(50 \%)$ & $2(33 \%)$ & - \\
\hline Rehabilitation & $2(14 \%)$ & $3(21 \%)$ & $6(43 \%)$ & $2(14 \%)$ & $1(7 \%)$ \\
\hline Total & $5(11 \%)$ & $14(31 \%)$ & $11(25 \%)$ & $11(25 \%)$ & $3(7 \%)$ \\
\hline $\begin{array}{l}\text { For leadership/academic } \\
\text { management }\end{array}$ & $1(2 \%)$ & $8(17 \%)$ & $22(46 \%)$ & $17(35 \%)$ & - \\
\hline For clinical supervision & $2(4 \%)$ & $9(19 \%)$ & $16(33 \%)$ & $21(44 \%)$ & - \\
\hline For IPE and collaborative practices & $1(2 \%)$ & $13(27 \%)$ & $22(46 \%)$ & $12(25 \%)$ & - \\
\hline For information technology & $3(6 \%)$ & $16(33 \%)$ & $20(42 \%)$ & $9(19 \%)$ & - \\
\hline For medical simulation & $4(8 \%)$ & $17(35 \%)$ & $15(31 \%)$ & $12(25 \%)$ & - \\
\hline
\end{tabular}

Table 2. Quantitative results from questionnaires

To provide high quality IPE, educators must develop their own knowledge, skills and attitudes toward IPE and collaborative practices in healthcare. Specifically, they must develop and demonstrate a commitment to IPE and collaborative practices, credibility within one's interprofessional community, and confidence and flexibility for managing professional differences. ${ }^{13}$ Although the importance of interprofessional training for educators has been widely acknowledged, a review of gray and peer-reviewed literature on this topic failed to identify a single article that specifically addressed faculty development strategies for interprofessional education. ${ }^{14-17}$ Many educators feel unprepared in IPE contexts and struggle to articulate a clear conceptual understanding of the core principles of interprofessionalism. ${ }^{13}$

The results of our needs assessment align with these findings, suggesting that current and potential health professions educators both need and desire pedagogical content on IPE and collaborative practices. This demonstrable interest presents opportunities for integrating other learning opportunities within an IPE framework. One of the challenges for these programs will be to help educators develop practical teaching skills. It is therefore important not simply to offer theorybased content about IPE, but also to train educators in how to develop IPE activities for learners and provide them with appropriate tools to evaluate the impacts of their activities in ways that could inform best practices in IPE pedagogical design. In addition to ensuring that graduate programs in health professions education contain pedagogical content about IPE, it is critical that the program itself is truly embedded in IPE principles and that healthcare educators enrolled in such program represent a diversity of disciplines. 
A limitation of this research is that it was a small study undertaken in a single university setting. In addition, although we recruited study participants from all potential faculty, it is possible that those who were more open to IPE were more likely to participate and/or were more forthcoming and positive in the focus groups. The actual results of this program - including whether or not it effectively provides IPE to a diversity of learners remain to be seen.

In conclusion, while our findings support the receptiveness of health professions educators for an interprofessional graduate program on health professions education, it also highlights the importance of developing research capacity within the IPE field. More research is needed to provide evidence-based principles and strategies that can be applied by health educators for improving current IPE curriculum and ensuring the development of a healthcare workforce equipped to engage in interprofessional collaboration.

\section{Acknowledgments}

The authors gratefully acknowledge the contributions of Dr. Danielle Saucier, MD, who led the original needs assessment and provided us with access to the data for this article and Dr Luc Côté, $\mathrm{PhD}$, who revised measurement tools and focus groups procedures.

\section{Keywords}

Interprofessional education, needs assessment, mixed methods, flexible instructional design

\section{Notes on Contributors}

EMMANUELLE CAREAU, PhD, OT, is an Assistant Professor in the Department of Rehabilitation, Faculty of Medicine, Université Laval, Québec City, Canada, a Research Scientist in the Centre for Interdisciplinary Research in Rehabilitation and Social Integration (CIRRIS), Québec City, Canada, and Director of Research in the Réseau de Collaboration sur les Pratiques Interprofessionnelles en Santé et Services Sociaux (RCPI), Québec City, Canada.

ISABELLE SAVARD, MA, $\mathrm{PhD}(\mathrm{c})$, is an Instructional Designer at the Office of Education and Continuing Professional Development, Faculty of Medicine, Université Laval, Québec City, Canada and a $\mathrm{PhD}$ candidate in the Cognitive informatics program at TELUQ, UQAM, Montreal, Canada.

HOLLY O. WITTEMAN, PhD, is an Assistant Professor in the Department of Family and Emergency Medicine, Faculty of Medicine, Université Laval, Québec City, Canada, an Assistant Professor and Director of Research in the Office of Education and Continuing Professional Development, Faculty of Medicine, Université Laval, Québec City, Canada, and a Research Scientist in the Research Centre of the CHU de Québec, Québec City, Canada.

All authors contributed equally and are listed alphabetically. 


\section{References}

1. Frenk J, Chen L, Bhutta ZA, Cohen J, Crisp N, Evans T, et al. Health professionals for new century: transforming education to strengthen health systems in an interdependant world. The Lancet 2010.

2. Aretz HT. Some thoughts about creating healthcare professionals that match what societies need. Med Teacher 2011; 33: 608-613.

3. Gibbs T, McLean M. Creating equal opportunities: the social accountability of medical education. Med Teacher 2011; 33: 620625 .

4. Gruppen LD, Mangrulkar RS, Kolars JC (2012) The promise of competency-based education in the health professions for improving global health. Human Resources for Health 2012; 10: 43.

5. Hirsh D, Walters L, Poncelet AN. Better learning, better doctors, better delivery system: possibilities from a case study of longitudinal integrated clerkships. Med Teacher 2012; 34: 548-554.

6. Armstrong EG, Barsion SJ. Creating "innovator's DNA" in health care education. Acad Med 2013; 88: 343-348.

7. Kaprielian VS, Silberberg M, McDonald MA, Koo D, Hull SK, et al. Teaching population health: a competency map approach to education. Acad Med 2013; 88: 626-637.

8. Krueger RA, Casey MA. Focus groups: A Practical Guide for Applied Research. Thousand Oak, CA: Sage Publications; 2000.

9. Reeves S, Perrier L, Goldman J, Freeth D, Zwarenstein M. Interprofessional education: effects on professional practice and healthcare outcomes (update). The Cochrane Library 2013; 2013(3):1-47.

10. Zwarenstein M, Reeves S, Perrier L. Effectiveness of pre-licensure interprofessional education and post-licensure collaborative interventions. J Interprof Care 2005; 19 Suppl 1:148-65.

11. Olenick M, Allen LR. Faculty intent to engage in interprofessional education. $J$ Multidiscip Healthc 2013; 6:149-61.

12. Accreditation of Interprofessional Health Education Initiative (AIPHE). Interprofessional Health Education Accreditation Standards Guide. Canada: AIPHE, 2011.

13. Egan-Lee E, Baker L, Tobin S, Hollenberg E, Dematteo D, Reeves S. Neophyte facilitator experiences of interprofessional education: implications for faculty development. $J$ Interprof Care 2011; 25(5):333-8.
14. Steinert Y. Learning together to teach together: interprofessional education and faculty development. . J Interprof Care 2005; 19(Suppl 1):60-75.

15. Freeth D, Hammick M, Koppel I, Reeves S, Barr H. A critical review of evaluation of interprofessional education. London: Higher Education Academy Learning and Teaching Support Network for Health Sciences and Practice, 2002.

16. World Health Organization. Framework for Action on Interprofessional Education \& Collaborative Practice. Geneva, Switzerland: 2010.

17. Oandasan I, Reeves S. Key elements for interprofessional education, part 1: the learner, the educator and the learning context. $J$ Interprof Care 2005; 19(suppl 1):8-20. 